\title{
Proctitis, CTCAE
}

National Cancer Institute

\section{Source}

National Cancer Institute. Proctitis, CT CAE. NCI Thesaurus. Code C57857.

A disorder characterized by inflammation of the rectum. 